\title{
Fetal foot length for assessment of gestational age: a cross sectional study
}

\author{
Vaibhav Sharma*, Ruchi Saxena, Priyanka Gaur
}

Department of Obstetrics and Gynecology, S. P. Medical College, Bikaner, Rajasthan, India

Received: 04 June 2021

Revised: 18 July 2021

Accepted: 19 July 2021

\section{*Correspondence:}

Dr. Vaibhav Sharma,

E-mail: vaibhav.ankit.sharma12@gmail.com

Copyright: (C) the author(s), publisher and licensee Medip Academy. This is an open-access article distributed under the terms of the Creative Commons Attribution Non-Commercial License, which permits unrestricted non-commercial use, distribution, and reproduction in any medium, provided the original work is properly cited.

\begin{abstract}
Background: Fetal age actually begins at conception and an equivalent term is conceptional age. Uncertain gestational age (GA) has been associated with adverse pregnancy outcomes independent of maternal characteristics. The objective was to evaluate the accuracy of fetal foot length (FFL) in estimation of gestational age.

Methods: It was a cross sectional study. Trans abdominal ultrasound on 150 pregnant women with normal singleton pregnancies between 16 to 40 weeks was done to measure FFL. The relationship between GA and FFL was analysed by simple linear regression.

Results: A linear relationship was demonstrated between FFL and GA. (GA (in weeks)=7.490+0.393×FFL (in mm)) with significant correlation $(r=0.985, \mathrm{p}<0.001)$.

Conclusions: Ultrasonographic measurement of FFL is a reliable indicator of gestational age and can be a useful alternative to estimate GA when other routine biometric parameters are not conclusive.
\end{abstract}

Keywords: Fetal foot length, Gestational age, Ultrasound

\section{INTRODUCTION}

Fetal age actually begins at conception and an equivalent term is conceptional age. The menstrual age should be calculated from the conceptional age, based on the assumption of mid-cycle ovulation,

menstrual age $=$ conceptional age +14 days .

Accurate knowledge of gestational length at delivery helps in making appropriate management decision which may assist obstetricians in appropriately counselling women who are at risk of a preterm delivery about likely neonatal outcomes and is also essential in the evaluation of fetal growth and detection of intrauterine growth restriction and for counselling patients regarding the option of pregnancy termination. ${ }^{1}$
Uncertain GA has been associated with adverse pregnancy outcomes independent of maternal characteristics. In cases where pregnancy cannot be accurately dated by clinical evaluation and history, ultrasonography is accepted as the most useful and accurate tool for estimation of GA especially in the first and second trimester of pregnancy. USG is based on measurements of the fetus using size as an indirect indicator of menstrual age.

But there are situations where these parameters cannot be used like if the head is unusually rounded (brachycephalic) or unusually elongated (dolicocephalic), BPD measurements would overestimate or underestimate gestational age. It has been observed that variation in AC measurements in macrosomic and growth retarded fetuses occur due to differences in liver size and width of subcutaneous tissue. ${ }^{2}$ Femur achondroplasia leads to 
underestimation of FL and therefore, of GA. In such situations such as hydrocephalus, anencephaly, short limb dysplasia and in third trimester pregnancy when the head is already engaged, we have to use other parameters for estimation of gestational age. One of the useful parameters is FFL because it is easily assessed and measured easily.

In 1920, Streeter had shown that fetal foot has a characteristic pattern of normal growth and proposed that the fetal foot could be used to estimate GA. ${ }^{3}$

So, we undertook this study to determine the accuracy of FFL in estimating GA.

\section{METHODS}

\section{Study setting}

This was a hospital based prospective study. The study period was from November 2020 to February 2021 (4 months). The study was conducted in the department of obstetrics and gynecology, SP medical college and PBM associated group of hospitals, Bikaner, Rajasthan. The study group comprised of 150 pregnant females attending the OPD/ANC/IPD.

\section{Inclusion criteria}

Pregnant women with singleton pregnancy of gestational age 16-40 weeks, with known last menstrual period, with prior regular menstrual cycle and no history of vaginal bleeding in pregnancy were included in the study.

A total 150 pregnant women with normal singleton pregnancies between 16-40 weeks of gestation with known last menstrual period, with prior regular menstrual cycle and who were willing to be enrolled in the study were also included.

Pregnancies with oligohydramnios and polyhydramnios, women with multiple pregnancies, foot anomalies in the fetus, having medical disorders, conceived by artificial reproductive techniques and those on oral contraceptive pills in last 3 months prior to conception were excluded from the study.

Transabdominal ultrasound scan was done FFL were measured and GA according to it was calculated. Data were collected using pre tested proforma. Statistical analysis was done using MS excel and SPSS software. The relationship between GA in weeks to FFL in millimetres (mm) was analysed by simple linear regression for a given GA, predicted values were obtained for the 5th, 50th and 95th percentiles to develop a nomogram.

\section{Statistical analysis}

After taking ethical approval, appropriate statistical analysis was done using Microsoft excel and statistical software SPSS and data were analysed with the help of figures, proportions, mean $\pm \mathrm{SD}$ and percentiles.

\section{RESULTS}

Table1 shows that majority $(50.7 \%)$ of cases were in the age group of $21-25$ years, $31.3 \%$ cases were in the age group of 26-30 years while least (4.7\%) number of cases were $>30$ years in age. The mean age of the study group was $24.51+3.80$ years.

In the study group 54\% cases were primigravida while $46 \%$ cases were multigravida.

In the study group of 150 females, majority (36\%) of the cases had BMI between $25-29.99 \mathrm{~kg} / \mathrm{m}^{2}$ while least number of cases $(31.3 \%)$ had BMI $>30 \mathrm{~kg} / \mathrm{m}^{2}$. The mean BMI of the study group was $27.79 \pm 4.16 \mathrm{~kg} / \mathrm{m}^{2}$.

Table 2 demonstrates the maximum and minimum measurement of FFL (in mm) as well as mean FFL of the study group at various GA.

In the study group, of the 3 cases having GA 16 weeks, the maximum and minimum FFL were $23 \mathrm{~mm}$ and $18.5 \mathrm{~mm}$ respectively and the mean FFL at 16 weeks of GA was $21.50 \pm 2.59 \mathrm{~mm}$. Similarly, of the 4 cases having GA 40 weeks, the maximum and minimum FFL were $83 \mathrm{~mm}$ and $68 \mathrm{~mm}$ respectively and the mean FFL at 40 weeks of gestation was $78.50 \pm 7.04 \mathrm{~mm}$.

A linear relationship between FFL and GA was obtained by simple linear regression analysis with high degree of correlation $(\mathrm{r}=0.985, \mathrm{p}<0.001)$ (Figure 1). The below equation can be used to derive the GA from FFL.

$y=7.490+0.393 x$

where,

$\mathrm{y}=\mathrm{GA}$ in weeks,

$\mathrm{x}=\mathrm{FFL}$ in $\mathrm{mm}$.

Table 1: Distribution of cases according to general characteristics.

\begin{tabular}{|lll|}
\hline Characteristics & Number & $\%$ \\
\hline Age group (in years) & & \\
\hline $18-20$ & 20 & 13.3 \\
\hline $21-25$ & 76 & 50.7 \\
\hline $26-30$ & 47 & 31.3 \\
\hline
\end{tabular}




\begin{tabular}{|lll|}
\hline Characteristics & Number & $\%$ \\
\hline$>30$ & 7 & 4.7 \\
\hline Total & 150 & \\
\hline Mean \pm SD & $24.51 \pm 3.80$ & \\
\hline Gravida & & 54.0 \\
\hline Primi & 81 & 46.0 \\
\hline Multi & 69 & \\
\hline Total & 150 & - \\
\hline BMI $\left(\mathbf{k g} / \mathbf{m}^{\mathbf{2}}\right)$ & & 32.7 \\
\hline$<18.5$ & 0 & 36.0 \\
\hline $18.50-24.99$ & 49 & 31.3 \\
\hline $25.00-29.99$ & 54 & \\
\hline$>30$ & 47 & \\
\hline Total & 150 & \\
\hline Mean \pm SD & $27.79 \pm 4.16$ & \\
\hline
\end{tabular}

Table 2: FFL (in mm) according to GA (in weeks).

\begin{tabular}{|llllll|}
\hline $\begin{array}{l}\text { Gestational age } \\
\text { (weeks) }\end{array}$ & Number of cases & Lower limit & Upper limit & Mean & SD \\
\hline $\mathbf{1 6}$ & 3 & 18.50 & 23.00 & 21.50 & 2.59 \\
\hline $\mathbf{1 7}$ & 4 & 23.00 & 26.00 & 24.50 & 1.29 \\
\hline $\mathbf{1 8}$ & 4 & 26.20 & 28.00 & 26.88 & 0.83 \\
\hline $\mathbf{1 9}$ & 5 & 25.00 & 31.00 & 28.16 & 2.39 \\
\hline $\mathbf{2 0}$ & 6 & 32.00 & 37.00 & 33.83 & 1.94 \\
\hline $\mathbf{2 1}$ & 3 & 35.00 & 38.00 & 36.33 & 1.53 \\
\hline $\mathbf{2 2}$ & 6 & 37.00 & 39.00 & 37.50 & 0.84 \\
\hline $\mathbf{2 3}$ & 5 & 35.00 & 46.00 & 41.00 & 4.06 \\
\hline $\mathbf{2 4}$ & 3 & 41.00 & 42.00 & 41.67 & 0.58 \\
\hline $\mathbf{2 5}$ & 5 & 44.00 & 57.00 & 48.40 & 5.18 \\
\hline $\mathbf{2 6}$ & 3 & 46.00 & 50.00 & 48.67 & 2.31 \\
\hline $\mathbf{2 7}$ & 6 & 49.00 & 53.00 & 51.33 & 1.86 \\
\hline $\mathbf{2 8}$ & 7 & 50.00 & 55.00 & 52.86 & 2.12 \\
\hline $\mathbf{2 9}$ & 8 & 55.00 & 60.00 & 57.63 & 1.92 \\
\hline $\mathbf{3 0}$ & 7 & 51.00 & 59.00 & 56.86 & 2.73 \\
\hline $\mathbf{3 1}$ & 7 & 61.00 & 63.00 & 62.29 & 0.76 \\
\hline $\mathbf{3 2}$ & 10 & 57.00 & 67.00 & 61.70 & 3.27 \\
\hline $\mathbf{3 3}$ & 10 & 60.00 & 75.00 & 64.50 & 4.70 \\
\hline $\mathbf{3 4}$ & 5 & 65.00 & 71.00 & 67.60 & 2.30 \\
\hline $\mathbf{3 5}$ & 8 & 62.00 & 72.00 & 67.50 & 3.21 \\
\hline $\mathbf{3 6}$ & 14 & 69.00 & 73.00 & 71.49 & 1.00 \\
\hline $\mathbf{3 7}$ & 5 & 76.00 & 77.50 & 76.70 & 0.67 \\
\hline $\mathbf{3 8}$ & 6 & 78.00 & 80.00 & 79.00 & 0.63 \\
\hline $\mathbf{3 9}$ & 6 & 79.00 & 81.00 & 80.17 & 0.75 \\
\hline $\mathbf{4 0}$ & 4 & 68.00 & 83.00 & 78.50 & 7.04 \\
\hline
\end{tabular}

Table 3: Nomogram of FFL ( $\mathrm{mm})$ according to percentile distribution.

\begin{tabular}{|llccc|}
\hline $\begin{array}{l}\text { Gestational age } \\
\text { (weeks) }\end{array}$ & Number of cases & \multicolumn{3}{l|}{$\begin{array}{l}\text { Foot length (in millimetres) according } \\
\text { to percentile distribution }\end{array}$} \\
\hline $\mathbf{1 6}$ & 3 & $\mathbf{5}$ & $\mathbf{5 0}$ & $\mathbf{9 5}$ \\
\hline $\mathbf{1 7}$ & 3 & 18.50 & 23.00 & 23.00 \\
\hline $\mathbf{1 8}$ & 4 & 23.00 & 24.50 & 26.00 \\
\hline $\mathbf{1 9}$ & 5 & 26.20 & 26.65 & 28.00 \\
\hline $\mathbf{2 0}$ & 6 & 25.00 & 27.80 & 31.00 \\
\hline
\end{tabular}




\begin{tabular}{|c|c|c|c|c|}
\hline \multirow{2}{*}{$\begin{array}{l}\text { Gestational age } \\
\text { (weeks) }\end{array}$} & \multirow[t]{2}{*}{ Number of cases } & \multicolumn{3}{|c|}{$\begin{array}{l}\text { Foot length (in millimetres) according } \\
\text { to percentile distribution }\end{array}$} \\
\hline & & 5 & $\mathbf{5 0}$ & 95 \\
\hline & & & & 00 \\
\hline 21 & 3 & 35.00 & 36.00 & 38.00 \\
\hline 22 & 6 & 37.00 & 37.00 & 39.00 \\
\hline 23 & 5 & 35.00 & 41.00 & 46.00 \\
\hline 24 & 3 & 41.00 & 42.00 & 42.00 \\
\hline 25 & 5 & 44.00 & 47.00 & 57.00 \\
\hline 26 & 3 & 46.00 & 50.00 & 50.00 \\
\hline 27 & 6 & 49.00 & 52.00 & 53.00 \\
\hline 28 & 7 & 50.00 & 53.00 & 55.00 \\
\hline 29 & 8 & 55.00 & 58.00 & 60.00 \\
\hline 30 & 7 & 51.00 & 57.00 & 59.00 \\
\hline 31 & 7 & 61.00 & 62.00 & 63.00 \\
\hline 32 & 10 & 57.00 & 61.00 & 67.00 \\
\hline 33 & 10 & 60.00 & 62.00 & 75.00 \\
\hline 34 & 5 & 65.00 & 68.00 & 71.00 \\
\hline 35 & 8 & 62.00 & 69.00 & 72.00 \\
\hline 36 & 14 & 69.00 & 71.45 & 73.00 \\
\hline 37 & 5 & 76.00 & 77.00 & 77.50 \\
\hline 38 & 6 & 78.00 & 79.00 & 80.00 \\
\hline 39 & 6 & 79.00 & 80.0 & 81.00 \\
\hline 40 & 4 & 68.00 & 81.5 & 83.00 \\
\hline
\end{tabular}

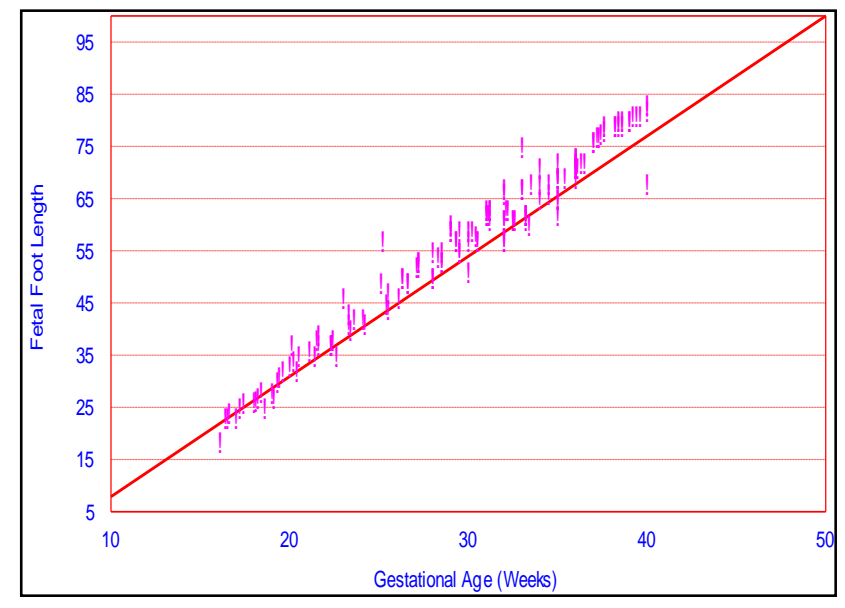

Figure 1: Correlation of FFL (mm) with GA (weeks).

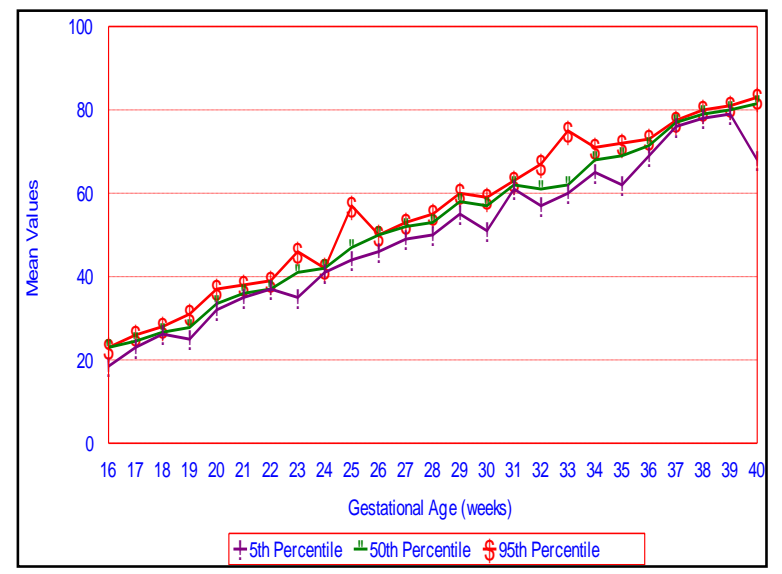

Figure 2: Percentile values (5th, 50th and 95th) for FFL from 16-40 weeks of gestation.
A nomogram of FFL with predicted values at 5th, 50th and 95th percentiles at various gestational age was obtained (Table 3) (Figure 2).

\section{DISCUSSION}

Ultrasonographic assessment of fetal GA has various clinical applications. Fetal biometry is useful for screening and diagnosing growth disturbances as well as structural and genetic abnormalities. But there are situations such as hydrocephalus, hydrops fetalis, short limb dysplasia where measurement of conventional parameters (biparietal diameter, head circumference, abdominal circumference and femur length) have some limitations or cannot be used. One useful alternative is measuring FFL. The technique of measurement is simple and it can be easily performed with good reliability.

The mean age of females in our study was $24.51 \pm 3.80$ years which is similar to that in the study of Hebbar et al which was 24.7 years while the mean age in the study of Ainani et al was higher $(27.03 \pm 4.23$ years $) .,{ }^{4,5}$

The mean BMI of females was $27.79 \pm 4.16 \mathrm{~kg} / \mathrm{m}^{2}$ which was higher than that in the study of Malik et al was 25.07 $\mathrm{kg} / \mathrm{m}^{2}{ }^{6}$ 
The mean sonographic FFL at 16 weeks was $21.50 \pm 2.59$ $\mathrm{mm}$ which is similar to the values obtained by Goldstein et al $(23 \pm 2.3 \mathrm{~mm})$ and Mukhia et al $(22 \mathrm{~mm})^{7,8}$

The mean sonographic FFL at 40 weeks was $78.50 \pm 7.04$ $\mathrm{mm}$ which was lower than that observed by Yuksel et al $(81.67 \pm 1.2 \mathrm{~mm}){ }^{9}$

In our study the minimum and maximum FFL at 16 weeks were $18.5 \mathrm{~mm}$ and $23.0 \mathrm{~mm}$ respectively which was similar to study results of Yuksel et al. ${ }^{9}$ The minimum FFL at 40 weeks in our study was $68.00 \mathrm{~mm}$ which was less than that obtained by Yuksel et al $(80 \mathrm{~mm})$ and the maximum FFL at 40 weeks observed in our study and that in the study of Yuksel et al is same, $83 \mathrm{~mm} .{ }^{9}$

In our study, a linear relationship between FFL and GA was seen $(r=0.985, p<0.01)$.

$y=7.490+0.393 x$

where,

$\mathrm{y}$ is gestational age in weeks

$\mathrm{x}$ is fetal foot length in $\mathrm{mm}$.

The results of our study was consistent with the studies done by Ainani et al, Joshi et al, Gameraddin et al and Pandey et al which showed a strong linear relationship between FFL and GA with high degree of correlation., 12

A nomogram for FFL was obtained with predicted values at 5th, 50th and 95th percentiles at various GAs in our population which is similar to the nomograms developed by Hebber et al, Joshi et al and Meirowitz et al. ${ }^{4,10,13}$ This showed that our FFL was comparable to that of western population.

The limitation of the present study was its small sample size. Therefore, results of our study needed to be confirmed in larger COHORT of patients to provide conclusive evidence regarding the use of FFL for estimation of GA.

\section{CONCLUSION}

Our study shows a linear relationship between FFL and GA with significant correlation between them. Thus ultrasonographic measurement of FFL is a reliable indicator of GA and can be a useful alternative to estimate gestational age when other routine parameters are not conclusive.
Funding: No funding sources

Conflict of interest: None declared

Ethical approval: The study was approved by the Institutional Ethics Committee

\section{REFERENCES}

1. Kalish RB, Chervenak F. Sonographic determination of gestational age. TMJ. 2009;59(2):202-8.

2. MacGregor SN, Sabbagha RE. Assessment of gestational age by ultrasound. Glob Libr Women Med. 2008:1756-2228.

3. Streeter G. Weight, sitting height, head size, foot length and menstrual age of human embryo. Contrib Embryol. 1920;11:143-70.

4. Hebbar S, Kopal S, Adiga P, Rai L. Fetal foot length throughout gestation: a nomogram. Sri Lanka J Obstet Gynecol. 2013;35(2):58-61.

5. Ainani R, Mital P, Chaudhary K, Kharbas U, Sonkhya $\mathrm{P}$, Sethi S, et al. A cross sectional study to evaluate foetal foot and femur length and femur/foot length ratio for estimation of gestational age at a tertiary care center. East African Scho J Med Sci. 2019;2(3):15363.

6. Malik BA, Ibrahim M, Ali Q, Yousef M, Alshammari QT, Jastaniah S. Use of foot measurements as sonographic parameters for estimation of fetal age. Open J Med Imaging. 2017;7(4):248-62.

7. Goldstein I, Reece A, Hobbins JC. Sonographic appearance of the feet heel ossification centers and foot length measurements provide independent markers for gestational age estimation. Am J Obstet Gynecol. 1988;159(4):923-6.

8. Mukhia R, Mukherjee A, Sabnis A. Determination of gestational age of human foetuses from crown heel length, crown rump lengh, foot length and abdominal circumference. Int J Rec Sci Res. 2016;7(1):8164-6.

9. Yuksel K, Gunyeli I, Doganay M, Ugur M, Mollamahmutoglu L. Ultrasonographic assessment of the fetal foot length for gestational age estimation. Gynecology Obstetric Reprod Med. 2006;12(1):27-9.

10. Joshi KS, Marahatta SB, Karki S, Tamrakar S, Shrestha NC. Fetal foot length and femur/foot length raio: a significance in Nepalese context. Nepalese J Radiol. 2011;1(1):15-22.

11. Gameraddin G, Suliman S, Yousef Y. Evaluation of gestational age with fetal foot length using ultrasonography. J Am Sci. 2014;10:5-7.

12. Pandey VD, Singh V, Nigam GL, Usmani Y, Yadav Y. Fetal foot length for assessment of gestational age: A comprehensive study in North India. Sch J App Med Sci. 2015;3(1):139-44.

13. Meirowitz NB, Ananth CV, Smulian JC, McLean DA, Guzman ER, Vintzileos AM. Foot length in fetuses with abnormal growth. J Ultrasound Med. 2000;19(3):201-5.

Cite this article as: Sharma V, Saxena R, Gaur P. Fetal foot length for assessment of gestational age: a cross sectional study. Int J Reprod Contracept Obstet Gynecol 2021;10:3153-7. 